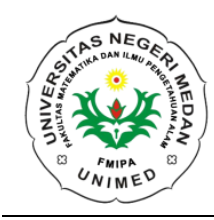

\author{
JURNAL EINSTEIN \\ Jurnal Hasil Penelitian Bindang Fisika \\ Available online http://jurnal.unimed.ac.id/2012/index.php/einsten \\ e-issn: $2407-747 x$, p-issn $2338-1981$
}

\title{
SINTESIS DAN KAKTERISASI ATKKS/KOMPON KARET/POLIPROPILENA SEBAGAI BAHAN TERMOPLASTIK ELASTOMER
}

\author{
A.H.Sinaga dan E.M.Ginting \\ Jurusan Fisika, Fakultas Matematika dan Ilmu Pengetahuan Alam, Universitas Negeri Medan, \\ Indonesia \\ Angelinhsinaga@gmail.com \\ Diterima September 2018; Disetujui Oktober 2018; Dipublikasikan November 2018
}

\begin{abstract}
ABSTRAK
Sintesis dan karakterisasi Abu Tandan Kosong Kelapa Sawit (ATKKS) bertujuan untuk mengetahui sifat mekanik campuran ATKKS/kompon karet/Polipropilena dengan variasi komposisi ATKKS $(0,2,4,6,8)$ phr. Menggunakan alat internal mixer laboplastomil model 30 R150 dengan kecepatan putaran $60 \mathrm{rpm}$ selama 12 menit pada suhu $180^{\circ} \mathrm{C}$. Kemudian dilakukan cetak tekan panas dan tekan dingin menggunakan hot press dan cold press lalu dipotong dengan standar JIS K 6781 dan dilakukan uji mekanik menggunakan alat Universal Testing Machine (UTM). Berdasarkan analisa dari hasil pengujian sifat mekanik diperoleh sifat mekanik pada modulus elastisitas mengalami penurunan dengan bertambahnya jumlah komposisi ATKKS, begitu juga dengan kekuatan tarik. Dan mengalami peningkatan perpanjangan putus hingga pada komposisi ATKKS 6 phr.
\end{abstract}

Kata Kunci : ATKKS, Kompon karet, Sifat Mekanik, Polipropilena

\section{PENDAHULUAN}

Tanaman kelapa sawit (Elaeis guinensis Jack) berasal dari Nigeria, Afrika Barat, pada kenyatannya tanaman kelapa sawit hidup subur di luar daerah asalnya, seperti Malaysia, Indonesia, Thailand, dan Papua Nugini. Bahkan mampu memberikan hasil produksi per hektar yang lebih tinggi. Indonesia merupakan penghasil utama minyak sawit. TKS merupakan salah satu limbah padat industri kelapa sawit. Tandan kosong sawit juga menghasilkan serat kuat sebagai bahan pengisi dalam produk serat berkaret, diantaranya jok mobil, matras dan papan komposit. (Aulia, dkk., 2013).

Penggunaan karet alam yang meningkat disebabkan oleh kelembutan alaminya dan kemudahan pembentukannya. Bagaimanapun, bahan pengisi perlu ditambahkan dengan maksud untuk menyiasati sifat-sifat alami yang tidak dikehendaki sehingga didapat suatu produk seperti yang diinginkan (Cifriandi, dkk., 2011). Karet jenis SIR-20 merupakan karet alam yang banyak diserap pasar internasional, sehingga peneliti menggunakan karet alam SIR-20 dalam penelitian ini. Agar dihasilkan barang jadi karet yang layak digunakan terlebih dulu karet mentah dicampur dengan bahan kimia karet lain, lalu divulkanisasi. Campuran antara karet dengan bahan-bahan tersebut dikenal dengan nama kompon karet (Nuyah dan Rahmaniar, 2013). Untuk mengingkatkan sifat fisik dan mekanik, karet alam dimodifikasi menjadi bahan termoplastik elestromer. Bahan termoplastik elestromer disintesis dengan cara mereaksikan karet alam sebagai elastromer dengan bahan termoplastik (Sudirman, dkk., 2000).

PP memiliki titik leleh yang tinggi, tahan korosi, mudah diproses, biaya prosesnya murah, 
mudah diperoleh dipasaran, serta dapat didaur ulang, sehingga banyak diaplikasikan untuk perabotan rumah tangga (Amalia, dkk., 2014). Untuk meningkatkan kualitas polipropilena rekayasa yang biasa digunakan dengan menambahkan karet.

(Bukit, 2011) dan (Ningsih, dkk., 2012), menggunakan PP modifikasi sebagai polimer komposit biodegradable. (Dwivedi, dkk., 2014) menggunakan PP sebagai serat untuk meningkatkan kekuatan lentur beton (Banon, 2016) menggunakan PP sebagai perekat untuk pembuatan papan komposit.

\section{METODE PENLITIAN}

\section{Alat dan Bahan}

Bahan yang digunakan adalah ATKKS dari PT.DPI (Dhajaja Putra Indonesia), Karet SIR 20, Wax, sulfur, Carbon black N330 dari Pusat Penelitian Karet Medan, MBTS, TMTD, IPPD, Asam stearat, Polipropilena produksi singapur, PP-g-MA dari jepang.

Alat yang digunakan adalah Two roll mixing, Internal mixer laboplastomill model 30 R150, Universal testing mechanic model larryee wdw 10, alat tekan panas dingin dan tekan dingin 37 ton dari Genno Jepang.

\section{PROSEDUR PENELITIAN}

Pembuatan kompon karet dilakukan dengan mencampurkan karet SIR 20 dan bahanbahan kimia (carbon black, wax, sulfur, asam stearat, ZnO, IPPD, TMTD, MBTS) menggunakan two roll mixing dengan formula pada tabel 1 . Karet SIR 20 digiling menggunakan two roll mixing selama 5 menit hingga karet menjadi remah, lalu diikuti dengan penambahan wax dan carbon black, setelah tercampur rata dilanjutkan dengan menambahkan $\mathrm{ZnO}$, Asam stearat, IPPD dan sulfur. Penggilingan tetap berlanjut dan pada menit ke 18 ditambahkan TMTD dan MBTS. Proses pencampuran dihentikan setelah 5 menit seluruh bahan tercampur dengan rata. Kompon karet yang diperoleh akan digunakan untuk pencampuran termoplastik elastomer.
Tabel 1. Formula Pencampuran Kompon Karet

\begin{tabular}{cccc}
\hline Bahan & $\begin{array}{c}\text { Komp } \\
\text { osisi } \\
\text { Bahan } \\
(p h r)\end{array}$ & $\begin{array}{c}\text { Waktu } \\
\text { Pencam } \\
\text { puran } \\
\text { (Menit) }\end{array}$ & $\begin{array}{c}\text { Fungsiny } \\
\text { a }\end{array}$ \\
\hline Karet SIR 20 & 100 & 0 & Binder \\
ZnO & 5 & 5 & Activator \\
Asam & 2 & 10 & Activator \\
Stearat & 10 & 15 & Filler \\
Carbon & 2 & 20 & Antioxida \\
Black & 1,5 & 25 & $n$ \\
IPPD & 3 & 30 & Antilux \\
Wax & 1,5 & 35 & C.A \\
Sulfur & 2,5 & 40 & Accelator \\
TMTD & & & Accelator \\
MBTS & & & \\
\hline
\end{tabular}

Pembuatan Termoplastik Elastomer dengan Pencampuran ATKKS/Kompon Karet/Polipropilena menggunakan alat internal mixer laboplastomil dengan kecepatan $60 \mathrm{rpm}$ pada suhu $180^{\circ} \mathrm{C}$ dengan formulasi campuran bahan pembuatan termoplastik elastomer yang terdapat pada tabel 2. dan waktu pencampuran bahan termoplastik elastomer terdapat pada tabel 3. Setelah bahan dicampur, dilakukan cetak tekan panas dan tekan dingin. Lalu sampel dipotong dengan standar JIS K6781 untuk dikarakterisasi sifat mekanik termoplastik elastomer menggunakan universal testing mechanic model larryee $\mathrm{wdw} 10$.

Tabel 2. Formulasi Campuran Bahan Pembuatan Termoplastik Elastomer

\begin{tabular}{lccccc}
\hline \multirow{2}{*}{ Bahan } & \multicolumn{5}{c}{ Formula Termoplastik (phr) } \\
\cline { 2 - 6 } & S0 & S1 & S2 & S3 & S4 \\
\hline Polipropilena & 88 & 86 & 84 & 82 & 80 \\
ATTKS & 0 & 2 & 4 & 6 & 8 \\
PP-g-MA & 2 & 2 & 2 & 2 & 2 \\
Karet SIR 20 & 10 & 10 & 10 & 10 & 10 \\
\hline
\end{tabular}

Tabel 3. Waktu Pencampuran Bahan Termoplastik Elastomer.

\begin{tabular}{cc}
\hline $\begin{array}{c}\text { Waktu } \\
\text { (Menit) }\end{array}$ & Vulkanisasi dinamik \\
\hline 3 & Proses pelelehan polipropilena \\
6 & NATTKS \\
9 & Kompon SIR 20 \\
10 & PP-g-MA \\
12 & Selesai \\
\hline
\end{tabular}




\section{HASIL DAN PEMBAHASAN}

\section{Karakterisasi mekanik}

Karakterisasi mekanik dilakukan untuk mengetahui sifat-sifat mekanik bahan termoplastik elastomer. Hasil karakterisasi uji sifat mekanik termoplastik elastomer dengan bahan ATKKS/kompon karet/polipropilena menggunakan Universal Testing Machine (UTM) didapatkan data modulus elastisitas, tegangan putus, kekuatan tarik, regangan putus variasi ATKKS $(0,2,4,6,8)$ phr seperti pada tabel 4.

Pada gambar 1. hubungan modulus elastisitas terhadap komposisi nanopartikel ATKKS menunjukkan penurunan dari 0 phr komposisi ATKKS hingga pada 4 phr komposisi ATKKS lalu menunjukkan peningkatan pada 6 phr komposisi ATKKS dan menurun kembali pada 8 phr ATKKS. Hal ini disebabkan oleh penambahan kompon karet sebagai matriks mempengaruhi nilai modulus elastisitas yang signifikan pada bahan termoplastik elastomer polipropilena.

Pada gambar 2. Grafik hubungan komposisi ATKKS terhadap kekuatan tarik, menunjukkan penurunan mulai dari komposisi ATKKS 0 phr hingga komposisi ATKKS 6 phr dan sedikit meningkat pada kompoisi $8 \mathrm{phr}$.

Pada gambar 3. Hunbungan perpanjangan putus pada komposisi $\operatorname{ATKKS}(0,2$, $4,6,8)$ phr menunjukkan bahwa nilai perpanjangan putus meningkat dari komposisi ATKKS 0 phr hingga komposisi ATKKS 6 phr namun menunjukkan penurunan yang signifikan pada komposisi ATKKS 8 phr. Komposisi ATKKS 6 phr memiliki nilai tegangan putus yang lebih besar dibandingkan komposisi ATKKS yang lainnya dengan nilai perpanjangan putus putus 264,73 \%GL, modulus elastisitas $682 \mathrm{Mpa}$, dan kekuatan tarik $24 \mathrm{Mpa}$.

(Bukit, 2013) melakukan sintesis dan karakterisasi nanopartikel zeolit alam sebagai filler termoplastik polipropilena memperoleh nillai mekanik pada komposisi nanopartikel zeolit alam $6 \mathrm{phr}$ kekuatan tarik 6,3 Mpa, perpanjangan putus 53,60 \%GL dan modulus young $11,6 \mathrm{Mpa}$. Abu sawit sebagai bahan pengisi yang diperoleh oleh (Bahruddin, 2010) memiliki sifat mekanik kekuatan tarik 9,6 $\mathrm{MPa}$ dan perpanjangan putus 209\%.

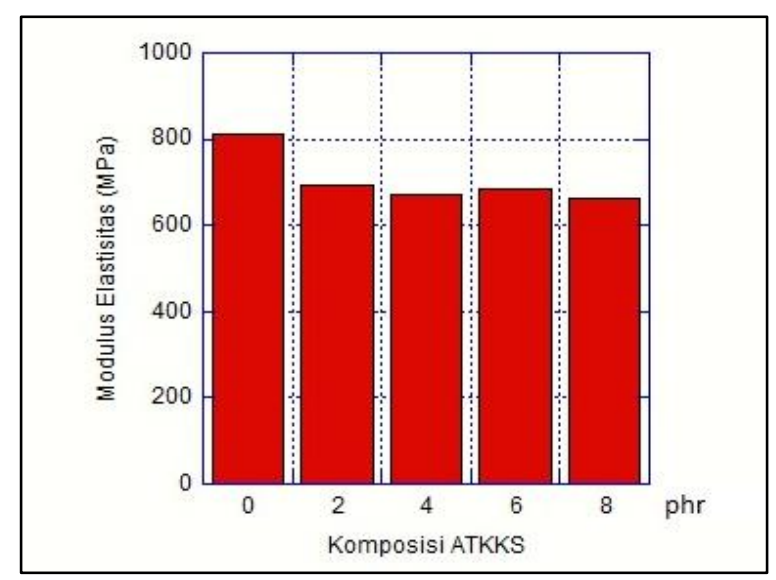

Gambar 1. Hubungan Modulus Elastisitas dengan Komposisi ATKKS

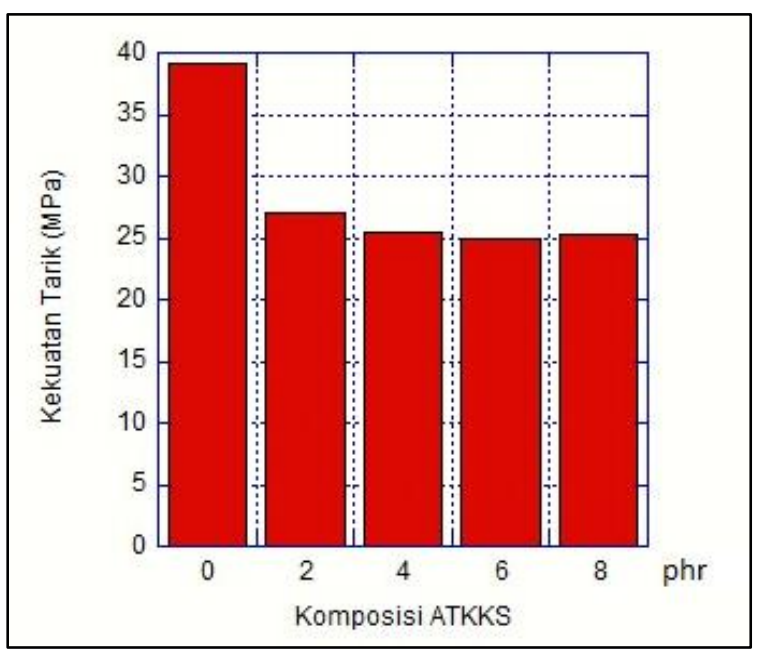

Gambar 2. Hubungan Kekuatan Tarik dengan Komposisi ATKKS

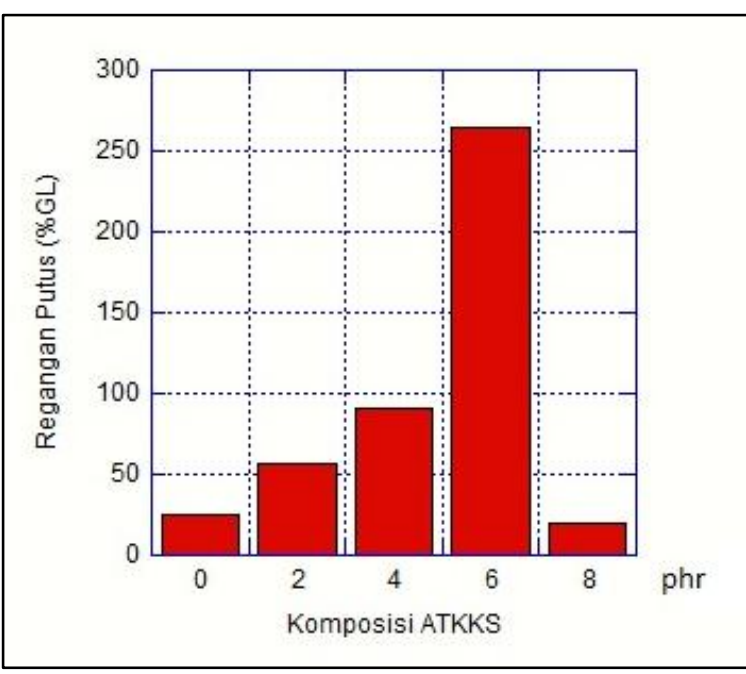

Gambar 3. Hubungan Perpanjangan Putus dengan Komposisi ATKKS 
Tabel 4. Hasil Karakterisasi Sifat Mekanik Termoplastik Elastomer

\begin{tabular}{cccc}
\hline Material & $\begin{array}{c}\text { Modulus } \\
\text { elastisita } \\
\text { s (MPa) }\end{array}$ & $\begin{array}{c}\text { Kekua } \\
\text { tan } \\
\text { tarik } \\
\text { (MPa) }\end{array}$ & $\begin{array}{c}\text { perpanja } \\
\text { ngan } \\
\text { putus } \\
\text { (\%GL) }\end{array}$ \\
\hline $\begin{array}{c}\text { PP/PP-g- } \\
\text { MA/kompon } \\
\text { karet/ATKKS } \\
\text { 0 phr }\end{array}$ & 811 & 39 & 24 \\
\hline PP/PP-g- & & & \\
MA/kompon & 693 & 26 & 56 \\
karet/ATKKS & & & \\
2 phr & & & \\
\hline PP/PP-g- & & & \\
MA/kompon & 671 & 25 & 90 \\
karet/ATKKS & & & \\
4 phr & & & \\
\hline PP/PP-g- & & & \\
MA/kompon & 682 & 24 & 264 \\
karet/ATKKS & & & \\
6 phr & & & \\
\hline PP/PP-g- & & & \\
MA/kompon & 664 & 25 & \\
karet/ATKKS & & & \\
8 phr & & & \\
\hline
\end{tabular}

\section{KESIMPULAN DAN SARAN}

Hasil karakterisasi mekanik termoplastik elastomer menunjukkan hasil campuran ATKKS/ Kompon karet/ Polipropilena/ PP-g-MA berdasarkan hasil analisa sifat mekanik pada komposisi ATKKS $6 \mathrm{phr}$, perpanjangan putus putus 264,73 \%GL, modulus elastisitas $682 \mathrm{Mpa}$, dan kekuatan tarik $24 \mathrm{Mpa}$.

\section{DAFTAR PUSTAKA}

Amalia, S.R., Fajarwati, K., Fitriawan, M., Aji, M.P., dan Yulianto, A., (2014), Kuat Tarik Komposit Polipropilena (PP) dengan Penguji Silika (SiO2), Seminar Nasional Mahasiswa Fisika, Semarang.

Aulia, F., Marpongahtun., Saharman, G., (2013), Studi Penyediaan Nanokristal Selulosa dari Tandan Kosong Kelapa Sawit, Jurnal Sinstia Kimia, 1(2): 1-7.

Bahruddin, Zahrina, I., Zulfansyah., Prayitno, A., dan Ahmad, A., (2010), Sifat dan
Morfologi Komposit Karet AlamPolipropilen yang Diperkuat dengan Sabut Buah Sawit dan Abu Sawit, Seminar Nasional dan Teknologi.

Banon, C., Sutanto, T, D., Gustian, I., Koharudin, I., dan Rahmi Widia (2016), Cangkang Buah Karet dengan Perekat Limbah Plastik Polipropilena Sebagai Alternatif Papan Partikel, Jurnal Kimia Riset, 1(2): 86-93.

Bukit, N., (2011), Pengolahan Zeolit Alam Sebagai Bahan Pengisi Nano Komposit Polipropilena Dan Karet Alam SIR -20 Dengan Kompatibiliser Anhidrida Maleat-Grafied-Polopropilena, Disertasi, Usu., Medan, 1-262.

Bukit, N., Frida, E., Harahap, M.H., (2013), Preparation Natural Bentonite In Nano Particle Material As FillerNanocomposite High Density Poliethylene (Hdpe), Chemistry and Materials Research, 3(13): 10-21.

Dwivedi, M., Mishra, S., and Singh, V., (2014), Effect of Polypropylene Fibres on Flexural Strength of M30 Grade Concrete, Journal of Mechanical and Civil Engineering, 11(4): 93-97.

Mohamad, N., Zainol, N.S., Rahim, F.F., Maulod, H.E.B, (2013), Mechanical and Morphologi Properties of Polypropylene/Epoxidized Natural Rubber Blends at Varios Mixing Ratio, Procedia Engineering 68, 439-445.

Ningsih, E.S., Mulyadi, S., dan Yetri Y., (2012), Modifikasi Polipropilena sebagai Polimer Komposit Biodegradabel dengan Bahan Pengisi Pati Pisang dan Sorbitol sebagai Plastisizer, Jurnal Fisika UNAND, 1 (1): 53-59.

Nuyah., Rahmaniar., (2013) pembuatan kompon karet dengan bahan pengisi arang cangkang sawit, jurnal dinamika penelitian industry, 24(2):114-121.

Sudirman, Handayani, A., Darwinto, T., dan Yulius, T., (2000), Struktur Mikro Dan Sifat Mekanik Komposit Elastromer Termoplastik-Timbal Oksida, Jurnal Mikroskopi Dan Mikroanalisis, 3(1): 17-20 